\title{
North Atlantic midwinter storm track suppression and the European weather response in ERA5 reanalysis
}

\author{
Estefania Montoya Duque ${ }^{1} \cdot$ Frank Lunkeit ${ }^{2} \cdot$ Richard Blender $^{2}$ (i)
}

Received: 25 March 2020 / Accepted: 4 January 2021 / Published online: 5 March 2021

(C) The Author(s) 2021

\begin{abstract}
In this study, we analyse the influence of North Atlantic midwinter storm track suppressions on European synoptic temperature and precipitation anomalies to determine the large-scale conditions relevant for the so-called Christmas thaw. We diagnose this relation in daily ERA5 reanalysis data in the spatial resolution of $0.25^{\circ}$ between 1979 and 2018 . To access synoptic time scales, a 3-10-day band-pass filter is applied. An index for the suppression is defined by the upper tropospheric Eddy Kinetic Energy (EKE) anomalies in the North Atlantic. We define the strong jet stream years as the year exceeding the $75 \%$ of the winter seasonal values at $250 \mathrm{hPa}$. In winters with strong jet activity, the storm track suppression is found, in agreement with the barotropic governor mechanism. Composites of European surface temperature and precipitation for low index values reveal weakly warmer conditions during winter (DJF) in Central Europe and the British Isles and a distinct cooling in Northern Europe. In the 1-month interval during December 15 to January 15, the warming is more pronounced. The clearest signal is the precipitation increase with a magnitude of $1 \mathrm{~mm} /$ day in the Mediterranean region.
\end{abstract}

\section{Introduction}

Storm tracks and jet streams influence climate and weather conditions in the Northern Hemisphere, see, e.g. Trigo (2006) and Woollings et al. (2010). Storm tracks are defined as regions of enhanced baroclinic wave activity in the midlatitudes, which is reflected as follows: (i) aggregates of individual storms on the surface or (ii) regions of enhanced Eddy Kinetic Energy (EKE) at the upper troposphere (Blackmon et al. 1977; Tamarin and Kaspi 2017). The Northern Hemisphere mid-latitudes have two centres of zonally elongated wave activity, one at the Pacific and the other one at the Atlantic basin (Nakamura 1992; Chang

Richard Blender

richard.blender@uni-hamburg.de

Estefania Montoya Duque

emontoyaduqu@student.unimelb.edu.au

Frank Lunkeit

frank.lunkeit@uni-hamburg.de

1 School of Earth Sciences, University of Melbourne, 253-283 Elgin St, Carlton, VIC, 3053, Australia

2 Meteorologisches Institut, Center for Earth System Research and Sustainability (CEN), Universität Hamburg, Bundesstr. 55, 20146 Hamburg, Germany
2001). Higher eddy activity is found over the northeastern Pacific and the northwestern Atlantic Ocean, specifically in the south of Greenland in the Labrador Sea region. The high EKE suggests a contribution of transient eddies to the meanfield of large-scale vorticity associated with low-pressure centres: the Aleutian low and the Icelandic low (Bengtsson et al. 2006).

Baroclinic waves, with typical time scales of 3-10 days, determine the storm track intensities, and so the weather conditions (Blackmon et al. 1977; Christoph et al. 1997). Baroclinic instability is a common theory for the relationship between the jet stream and the storm tracks. This theory explains wave growth in regions of enhanced baroclinicity, indicated by an increasing intensity of the jet stream (Christoph et al. 1997; Afargan and Kaspi 2017).

Observations suggest a midwinter eddy kinetic energy (EKE) suppression despite the enhanced baroclinicity, contradicting the linear theories (Nakamura 1992; Christoph et al. 1997). Both the Atlantic and Pacific storm track seem to have reduced EKE activity in the winter season, which becomes more apparent during years of high jet velocities (Afargan and Kaspi 2017). The Atlantic storm track has a weaker midwinter suppression than the Pacific storm track (Afargan and Kaspi 2017) which is explained by the weaker intensity and the weaker seasonal variation of the Atlantic jet. The authors find strong (weak) jets in winters with a positive (negative) North Atlantic Oscillation (NAO), which 
is mainly associated with a latitudinal displacement of the jet. General Circulation Models (GCM) can capture this midwinter minimum (Chang 2001; Deng and Mak 2005).

The midwinter minimum of the Northern Hemispheric storm tracks is at first sight surprising and counterintuitive (Deng and Mak 2005). The dynamic mechanism which reduces the baroclinic eddy growth rate was denoted as barotropic governor in numerical experiments (James and Gray 1986). These experiments revealed increased meridional barotropic shear and reduced baroclinic instability for reduced surface drag. James (1987) explained the reduced baroclinic growth in a two-level model by the change in the structure of the unstable modes, which loose their optimal configuration for energy extraction from the mean flow. The Lorenz energy cycle (Lorenz 1955) is altered since available potential energy feeds the zonal kinetic energy leading to a nonlinear reinforcement of the effect. The main change is the reduced conversion of zonal available energy to eddy kinetic energy (see the conceptual model in James and Gray 1986)

The key process connecting storm tracks and the surface climate are synoptic cyclones. These vortices are seen from a Lagrangian point of view, while waves, instabilities, and the storm tracks are a Eulerian measure. The storm track definition is based on a relatively simple and reproducible band-pass filtered variance of a twodimensional geopotential height or vorticity. On the other hand, synoptic cyclones are not uniquely defined and difficult to diagnose in data (Neu et al. 2013). The storm track as a measure of variability is replaced by the cyclone track (see, e.g. Blender et al. 1997). Depending on the location of this track, local weather conditions change (Bengtsson et al. 2006). For a recent review on storms in the North Atlantic and Europe, see Feser et al. (2015).

Synoptic studies indicate that baroclinic conditions are related to most heavy wintertime precipitation and strong surface winds (Blackmon et al. 1977). There is a wide range of literature that addresses the climate variability of the storm tracks using surface precipitation and air temperature, e.g. Blackmon et al. (1977), Rogers (1997), and Liao et al. (2018).

There are recurrent changes in weather conditions observed during winter. The so-called Christmas thaw (or singularity) in Central Europe denotes a temperature and precipitation anomaly between 15 December and 15 January. Singularities denote rare but recurrent short-term weather events in a restricted region. One of the first who confirmed the relation between the large scale circulation and local singularities was Wahl (1953), however, the statistical significance of singularities is still discussed (Godfrey et al. 2002). Brooks (1946) and Řezničkovả et al. (2007) described the surface weather conditions associated with the so-called singularities during Christmas time for given large-scale patterns (the so-called Grosswetterlagen). They found warm surface temperatures and more precipitation in England during weaker anticyclonic activity in the Czech Republic. A weak warming after Christmas was identified by Tomczyk (2016) in station data in Poland. In NOAAAVHRR satellite data in 1989-1996, Kästner and Kriebel (2001) observed a variability of the cloud cover reconcilable with a Christmas thaw.

The observation of a midwinter minimum in the activity in the Northern Hemispheric storm tracks may be the key to diagnose and explain the midwinter weather anomaly in Europe. However, the diagnostic of this mechanism is difficult since the midwinter minimum in the North Atlantic is weak, and the inter-annual variability in European winter weather is high. In addition, the complex continental orography in Europe may lead to local effects.

In this paper, we address the relation of North Atlantic midwinter suppression detected in the EKE to anomalies in the European weather. Weather is considered as synoptic variability and accessed by a 3-10-day band-pass filter. We use ERA5 reanalysis in the spatial resolution of $0.25^{\circ}$ between 1979 and 2018. We subject the EKE at $250 \mathrm{hPa}$ to an EOF analysis and define an index denoted as EMMI (EKE Midwinter Minimum Index) by the first principal component PC1. Composites of surface weather maps for the lowest $20 \%$ percentile of the EMMI during DJF and Christmas time reveal connections to precipitation and temperature.

The paper is organized as follows: The description of the data and methods are in Section 2. The Eulerian approach of the storm tracks, composites, correlations, and Empirical Orthogonal Functions is used to represent the singularities and connect them with general circulation patterns. The results are found in Section 3, and the discussion and the conclusions are in Section 4.

\section{Data and methods}

Our analysis is based on the ERA5 reanalysis dataset, available since 2019 (Hersbach et al. 2019). An advantage of ERA5 is the higher resolution $(31 \mathrm{~km})$ compared to ERAInterim $(79 \mathrm{~km})$. We use the following gridded 6 hourly data: wind fields at $250 \mathrm{hPa}$, surface air temperature at 2 $\mathrm{m}$, and surface total precipitation, available at Copernicus Climate Change Service (C3S) (2017). The time period of the data spans from 1979 to 2018. To assess synoptic scale variability, the variables are aggregated to a daily resolution and are band-pass filtered using a 3-10-day Lanczos filter (Duchon 1979). We like to summarize the following definitions. 
EKE The storm strack intensity is identified in our analysis by the Eddy Kinetic Energy (EKE):

$\mathrm{EKE}=\frac{1}{2}\left(\overline{u^{\prime 2}}+\overline{v^{\prime 2}}\right)$,

where $u^{\prime}$ and $v^{\prime}$ are the band-pass filtered zonal and meridional components of the wind at $250 \mathrm{hPa}$. To determine the EKE climatology and the mid winter suppressions, we use two measures in different areas.

EKE climatology The climatologal mean of the EKE is obtained in the The North Atlantic area delimited between $40^{\circ}-60^{\circ} \mathrm{N}$ and $70^{\circ}-10^{\circ} \mathrm{W}$. The spatial average of the daily data is smoothed with a 31-day running mean filter as in Afargan and Kaspi (2017).

EKE suppressions The suppressions of the EKE are determined by an EOF analysis in a wider North Atlantic region in $30^{\circ}-80^{\circ} \mathrm{N}$ and $70^{\circ}-10^{\circ} \mathrm{W}$. The daily EKE fields are subject to an EOF analysis.

EMMI To characterize the EKE suppressions by a daily index, we use the standardized principal component PC1 and denote it as EKE Midwinter Minimum Index (EMMI). We choose the $20 \%$ percentile of the EMMI to represent EKE suppressions.

Jet The jet strength is determined for seasonal means of the (unfiltered) zonal velocity $u$ at the latitude of the maximum monthly averaged zonal wind in $40^{\circ}-60^{\circ} \mathrm{N}, 70^{\circ}-10^{\circ} \mathrm{W}$ (as in Afargan and Kaspi (2017)). We select the strong and weak jet years using the winter seasonal conditions of the jet in the North Atlantic. The $25 \%$ and $75 \%$ percentiles represent the weak and strong years, respectively, as shown in Table 1. The jet strength is used to assess the impact of the barotropic governor mechanism.

European weather Synoptic scale near surface air temperature and total precipitation are used in the Euro-Atlantic sector in $30^{\circ}-80^{\circ} \mathrm{N}$ and $70^{\circ} \mathrm{W}$ to $22^{\circ} \mathrm{E}$; in the diagnostic we concentrate on land. The surface data is subject to a 3-10-day band pass (Lanczos) filter.

Significance The significance of the temperature and precipitation anomalies is determined by a two-sided MannWhitney test of the median changes. We choose the threshold $p<0.1$ for the $p$-value, which can be interpreted as $10 \%$ significance interval.

Table 1 List of years with strong (upper quartile) and weak (lower quartile) jet strength in $40^{\circ}-60^{\circ} \mathrm{N}, 70^{\circ}-10^{\circ} \mathrm{W}$

$\begin{array}{ll}\text { Strong } & 1984199319941999200820122014201520162018 \\ \text { Weak } & 1979198119921996199720042006201020112017\end{array}$

\section{Results}

In this section, we show results for the upper tropospheric EKE and define an index as a nondimensional measure of EKE intensity. We use this to determine composites of the European surface temperature and precipitation for two different time periods. The analysis is restricted to the Euro-Atlantic sector.

We begin with the climatology of the EKE to obtain an overall behaviour of the eddy activity. The climatological EKE is obtained by a spatial averaged and a temporal smoothing. The aim of this part is to demonstrate the decrease in EKE in winters with strong jets. The motivation of this analysis is confirm the barotropic governor as the dynamical mechanism. The daily variability in the EKE is assessed by an EOF analysis. Since the first EOF describes the spatial pattern of the storm track, we use the first principal component to define a daily index, which measures the EKE intensity in the North Atlantic. Low values of this index are used to stratify the surface climate during (i) the whole winter season (DJF), and (ii) during 15 December-15 January representing the period considered as Christmas time.

\subsection{EKE climatology}

The climatological annual cycle of the EKE averaged in the North Atlantic area $\left(40^{\circ}-60^{\circ} \mathrm{N}, 70^{\circ} \mathrm{W}-10^{\circ} \mathrm{W}\right)$ gives a first indication for a recurrent wintertime suppression (Fig. 1a). Obviously, the winter season is not indicated by a broad maximum. After the continuous increase until December, the EKE decays instantaneously and attains a weakly pronounced local minimum in February. In March and April, volatile weather announces the spring season. On the other hand, the jet strength continuously increases until the end of January and decreases afterwards. Thus, EKE appears to be suppressed during periods with high jet strength. The suppression is pronounced for winters with strong jets (Fig. 1b). For winters with weak jets (Fig. 1c), a suppression is absent and the EKE follows the jet strength in phase. These findings are in line with the so-called barotropic governor mechanism (James 1987).

Overall, the dependency of the seasonal averages of the EKE on the jet intensity is nonlinear (Fig. 2). We fitted the parabola:

$\mathrm{EKE}=\mathrm{EKE}_{0}+b\left(U-U_{\max }^{2}\right)$,

with the coefficients $\mathrm{EKE}_{0}=109.86 \mathrm{~m}^{2} / \mathrm{s}^{2}, b=-0.118$, and $U_{\max }=27.185 \mathrm{~m} / \mathrm{s}$. For low jet strengths, a positive correlation appears mostly in summer but also for a few winters with a weak jet consistent with Fig. 1c. For high jet strengths, negative correlations are found indicating the EKE suppression. These situations appear only in winter 

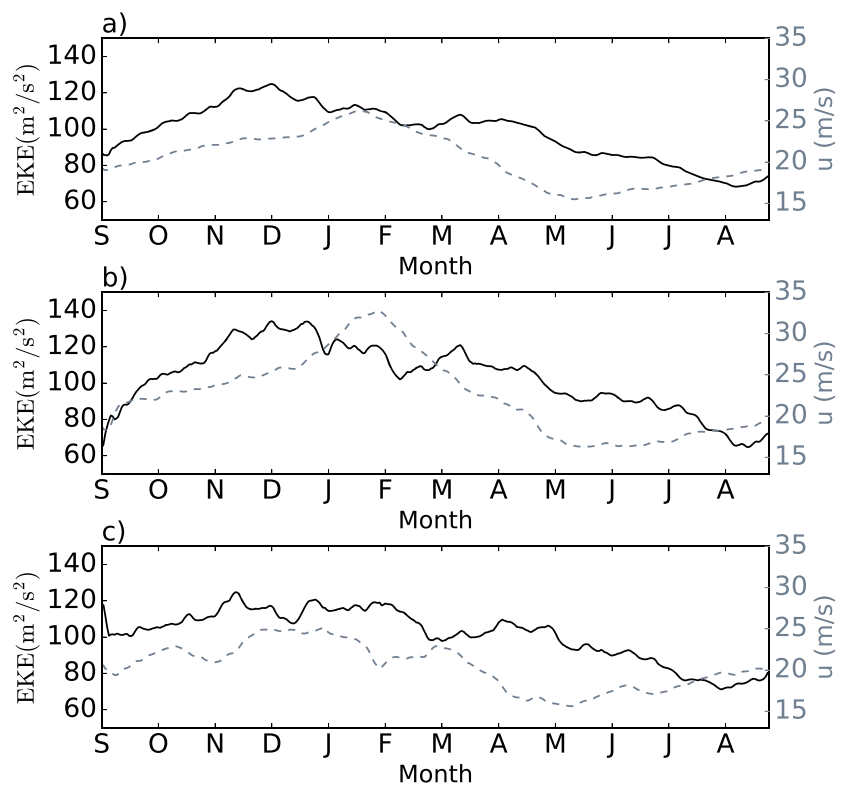

Fig. 1 Climatology of the Eddy Kinetic energy (EKE, $\left[\mathrm{m}^{2} \mathrm{~s}^{-2}\right]$ ) (solid) averaged in $40^{\circ}-60^{\circ} \mathrm{N}, 70^{\circ}-10^{\circ} \mathrm{W}$ and the maximum jet strength $u[\mathrm{~m} / \mathrm{s}]$ (dashed, right axis) in this region. The EKE climatology is obtained by a 31-day running mean filter. (a) All winters, (b) winters with strong jets, (c) winters with weak jets; see the list with strong and weak jet years in Table 1

seasons. This confirms the result of Afargan and Kaspi (2017), who found a decreasing linear behaviour for large jet strength in the winter months January-March (their Figure 5).

\subsection{EKE midwinter minimum index EMMI}

The spatial pattern of the first EOF1 represents the dominant mode of the EKE variability with a core between 40 and

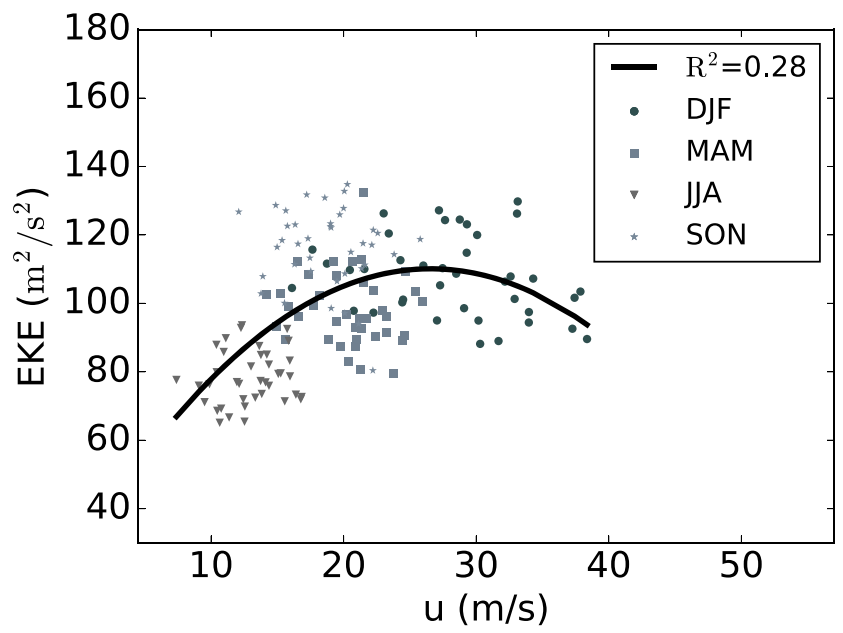

Fig. 2 Relation of the EKE and the jet strength in $40^{\circ}-60^{\circ} \mathrm{N}$, $70^{\circ}-10^{\circ} \mathrm{W}$ in different seasons as indicated. The solid curve is a parabolic fit in Eq. 2

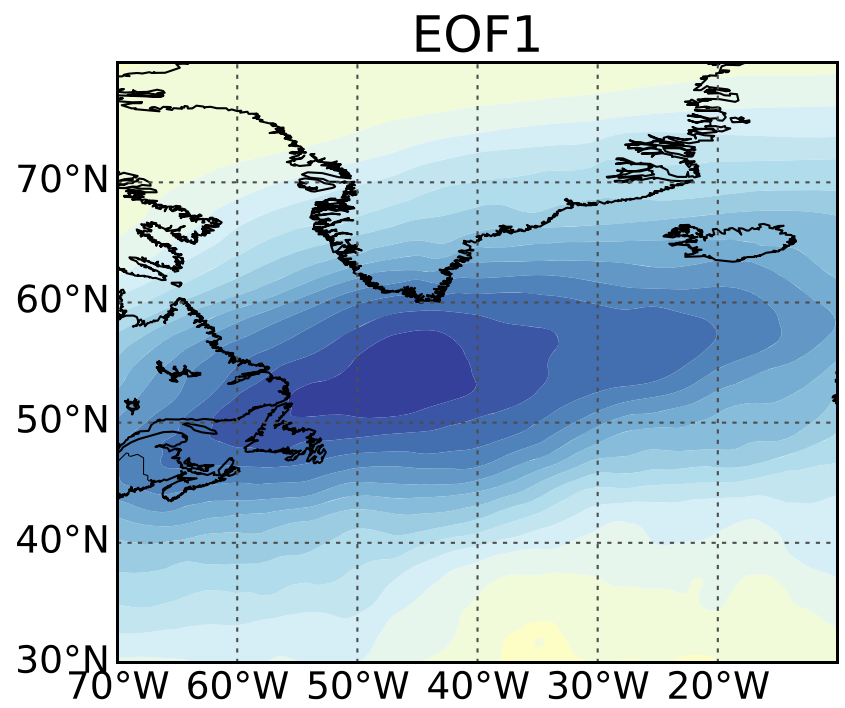

Fig. 3 First Empirical Orthogonal Functions EOF1 of the eddy kinetic energy (EKE) in the North Atlantic $\left(30^{\circ}-80^{\circ} \mathrm{N}, 70^{\circ} \mathrm{W}-10^{\circ} \mathrm{W}\right)$, using daily band-pass filtered DJF data in 1979-2018

$65^{\circ} \mathrm{N}$ across the Atlantic ocean, see Fig. 3. This EOF explains $21 \%$ of the total variance. The intensity pattern confirms the selection of the area for climatological EKE within $40-60^{\circ} \mathrm{N}$ in Section 3.1. The second empirical orthogonal function EOF2 explains $9.98 \%$ of the total variance and describes a meridional shift of the EKE intensity (not shown), similar to the North Pacific (Ma and Zhang 2018). Therefore, EOF2 does not contribute to the total intensity of the EKE activity. Thus, the midwinter suppression and its relation to the Euro-Atlantic weather are assessed by $\mathrm{PC} 1$ only. The standardized first principal component PC1 is denoted as EMMI (EKE Midwinter Minimum Index) and shown in Fig. 4. The 20\% percentile of the EMMI is chosen to represent EKE suppressions. Note that the EMMI time series is constructed with winter days

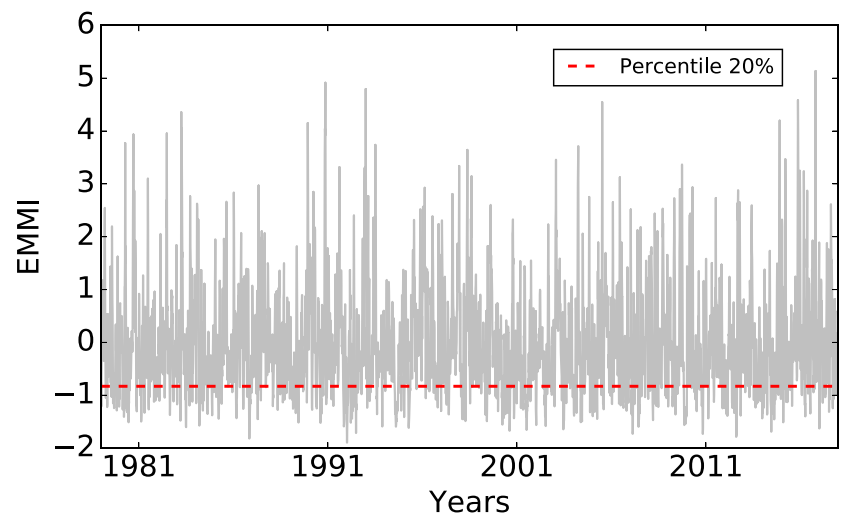

Fig. 4 EKE Midwinter Minimum index, EMMI, given by the standardized first principal component (PC1) of the eddy kinetic energy. The dashed horizontal line denotes the $20 \%$ percentile of the index values. The time series shows daily data in DJF only 
only. The data is positively skewed and reveals extremal behaviour which is beyond the scope of the present analysis.

\subsection{European weather anomalies}

We diagnose the response of the European weather to low EMMI values by compositing for episodes with anomalous low EKE. As a threshold to identify the midwinter suppression days, we use the $20 \%$ percentile of EMMI (see the horizontal dashed line in Fig. 4). We consider bandpass filtered surface temperature and precipitation fields in the Euro-Atlantic sector $\left(30^{\circ}-80^{\circ} \mathrm{N}, 70^{\circ}-10^{\circ} \mathrm{W}\right)$ with a focus on land. In the first part, we consider composites for the whole winter season (DJF), and in the second part, we restrict the composites to one month between 15 December and 15 January, the actual Christmas time. In this part, we aim at singularities which occur typically on short time scales between a few days and weeks within this period (Wahl 1953).

In the DJF composites, the surface temperature exhibits positive anomalies up to $0.1^{\circ} \mathrm{C}$ in Iberian Peninsula and Iceland, see Fig. 5a. An opposite impact is seen in Scandinavia where significant negative anomalies between $-0.2^{\circ}$ and $-0.3^{\circ} \mathrm{C}$ are found. This region suffers obviously from the absence of Atlantic cyclones. Central Europe is the transition zone between Southwest Europe and Scandinavia and displays low temperature anomalies during the EKE midwinter suppression, of about $-0.1^{\circ} \mathrm{C}$.

The DJF precipitation composite shows weak positive anomalies in a belt from Southern Italy to the British Isles, which are partly significant, Fig. 5 b. The increase in
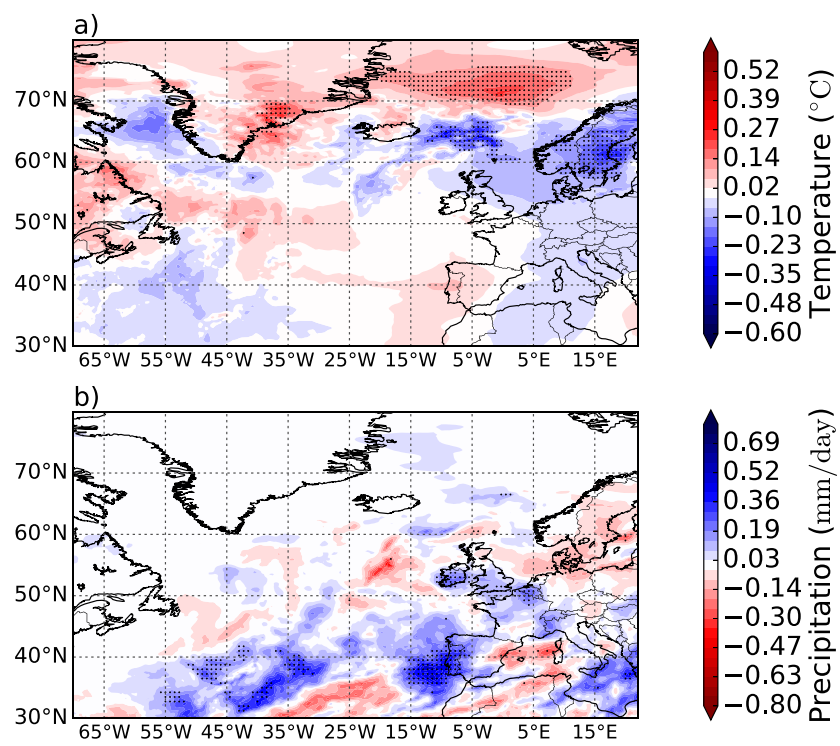

Fig. 5 Surface air temperature (a) and precipitation (b) anomaly in the composite during winter (DJF) obtained for days with low EMMI. Grid points with significant anomalies are marked by dots

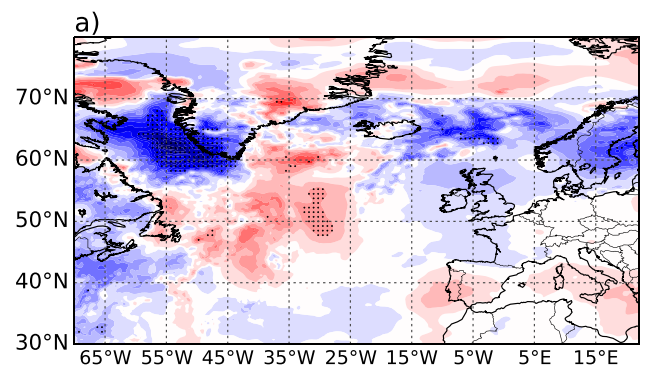

0.52

$0.39 \circlearrowright$

0.270

0.14

0.02

$-0.10 \frac{0}{0}$

-0.23 은

-0.35 ह

$-0.48 \stackrel{-0}{-0}$

$-0.60$

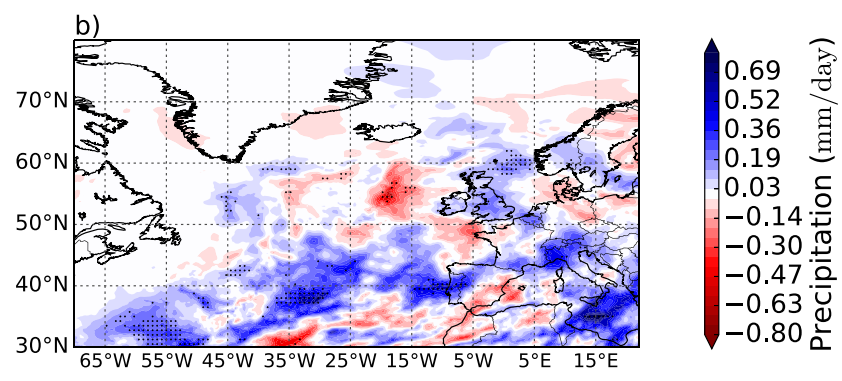

Fig. 6 Surface air temperature (a) and precipitation (b) anomaly in the composite during Christmas time, 15 December-15 January, for days with low EMMI. Grid points with significant anomalies are marked by dots

precipitation is between 0.2 and $0.3 \mathrm{~mm} /$ day in this region. In Central and Southeast Europe, precipitation does not seem to present changes.

If we restrict the temperature and precipitation composites to Christmas time (15 December to 15 January), see Fig. 6, the patterns reveal much more pronounced but insignificant anomalies. The surface temperature (Fig. 6a) is warmer with a magnitude of up to a tenth of a Celsius degree over the Iberian Peninsula and Italy. On the other hand, the central region has no changes in temperature.

The increase of precipitation in the Mediterranean, France, and the British Isles is distinct with magnitudes up to $0.8 \mathrm{~mm} /$ day (Fig. $6 \mathrm{~b}$ ). The pattern is similar to the DJF pattern (Fig. 5b), again with the highest values in the Mediterranean. These anomalies have the magnitude as the observed precipitation rate in the Mediterranean (about $1-2 \mathrm{~mm} /$ day, (Hatzianastassiou et al. 2016)). In Eastern Spain and Eastern Europe, however, precipitation is weakly reduced by $0.2 \mathrm{~mm} /$ day.

\section{Conclusions and discussion}

In summary, we determined the relation between the weak North Atlantic storm track intensity and European surface weather in winter. A motivation is to elucidate whether the large-scale circulation affects regional anomalies denoted as singularities during winter and the shorter timespan close to Christmas. The singularity is known as Christmas 
thaw denoting the surprising appearance of relatively warm and humid weather after Christmas. Since the events are weak and rare, this singularity is debated for statistical reasons. On the other hand, the mild weather in midwinter is counterintuitive and the dynamic origin is involved.

A possible dynamical mechanisms to understand this phenomenon is given by the barotropic governor (James 1987): the storm development by baroclinic instability is reduced in periods with high baroclinicity due to the wind shear. The development of mid-latitude cyclones is hindered since the available potential energy feeds the zonal kinetic energy. We find a pronounced storm track suppression in winters with a strong jet at $250 \mathrm{hPa}$.

We find a nonlinear dependency of the seasonal averages of the EKE on the jet intensity as in Afargan and Kaspi (2017). Mostly in summer, jet strengths are weak and positively correlated with EKE. For high jet strengths, mostly in winter, negative correlations are found related to EKE suppression.

The data used is the ERA5 reanalysis dataset in 19792018. We use daily data with the high $0.25^{\circ}$ resolution to assess details in European surface temperature and precipitation. The storm intensity is defined by the EKE in the upper troposphere at $250 \mathrm{hPa}$. The EKE average in the North Atlantic $\left(40^{\circ}-60^{\circ} \mathrm{N}, 70^{\circ}-10^{\circ} \mathrm{W}\right)$ shows an annual cycle with a reduction beginning in January leading to weak local minimum in February, although the jet strength still increases in accordance with the barotropic governor (James 1987).

To assess the dominant variability of the storm track intensity, we perform an EOF analysis based on daily bandpass filtered EKE in DJF. Since the first EOF is relevant for the storm track intensity, we use the first principal component PC1 to define an index EMMI (EKE Midwinter Minimum Index). Midwinter suppressions of the EKE are defined by the lowest 20\% EMMI values. During these midwinter suppressions, we determine composites of the weather in Europe during two periods; the whole 3-month winter (DJF) and the 1-month Christmas time, between 15 December and 15 January. The associated temperature and precipitation fields differ for the two averaging periods.

In the 3-month period (DJF), a warmer pattern stretches from Southern Europe towards Iceland. The anomalies reach $0.2^{\circ}$ C. Central Europe is a transition zone with vanishing temperature anomalies. In general, warmer temperatures are correlated with higher precipitation.

In the 1-month Christmas time, the warming dominates in Europe, even the cold anomaly in Scandinavia is drastically reduced. The precipitation anomaly pattern is more intense than in DJF. The increase in the Mediterranean is upto $1 \mathrm{~mm} /$ day. Note that the observed mean winter rainfall in the Mediterranean area $\left(0^{\circ}-20^{\circ} \mathrm{E}, 35^{\circ}-45^{\circ} \mathrm{N}\right)$ varies in the range of $1-2 \mathrm{~mm} /$ day (Hatzianastassiou et al. 2016).

In interpreting these results, we are aware of limitations of an analysis of weak and short events. Although they might be recurrent, they are not exactly in phase with the seasonal cycle and disappear in averages with fixed dates. Nevertheless, due to the widespread interest in singularities, and especially the Christmas thaw, we like to stress the most intense findings:

1. The precipitation anomalies in the Mediterranean between 15 December and 15 January, with a magnitude of 1 $\mathrm{mm} /$ day are in the range of the observed climatological rainfall rates $(1-2 \mathrm{~mm} /$ day) in this region. This impacts mostly Southern Italy and the Balkans.

2. The coldness of $-0.5^{\circ} \mathrm{C}$ in Scandinavia during DJF is the strongest temperature response Europe; in contrast to the other anomalies, this remains in the 1-month average 15 December-15 January.

Our results can be compared to a few studies of the Christmas thaw in Europe. Řezničkovà et al. (2007) analysed station data in the Czech Republic for 1961-2002 with shorter periods, e.g. the Christmas thaw in 26.-29. Dec. and deep winter in mid-January. For the Christmas thaw, warmer anomalies, without precipitation anomaly, and for deep winter, cold and dry anomalies were found. For the Czech Republic, we can confirm a cold anomaly in DJF. Tomczyk (2016) analysed the Christmas thaw in station data in Poland and found an insignificant warming, which is not confirmed by our analysis. An analysis of NOAA-AVHRR data in the Alpine region by Kästner and Kriebel (2001) for 1989-1996 showed a cloud cover variability at the end of December which agrees with a Christmas thaw.

Thus, the Christmas thaw appears to be a wetter, but not much warmer period according to this analysis in most parts of Europe. A complementary study could address the opposite relation, namely starting with a diagnostic of climate anomalies and compositing dynamic sources upstream.

Acknowledgements The authors like to thank the anonymous reviewer for helpful comments.

Author contributions All authors contributed to the design of the study and the interpretation. Emphasis of Estefania Montoya Duque was on diagnostics and graphics, Frank Lunkeit on physical diagnostics, and Richard Blender on the climatological embedding and writing.

Funding Open Access funding enabled and organized by Projekt DEAL. The study was funded by the Deutsche Forschungsgemeinschaft (DFG, German Research Foundation) under Germany's Excellence Strategy - EXC 2037 'CLICCS - Climate, Climatic Change, and Society' - Project Number: 390683824, contribution to the Center for Earth System Research and Sustainability (CEN) of Universität Hamburg. 


\section{Compliance with ethical standards}

Conflict of interest The authors declare that they have no conflict of interest.

Open Access This article is licensed under a Creative Commons Attribution 4.0 International License, which permits use, sharing, adaptation, distribution and reproduction in any medium or format, as long as you give appropriate credit to the original author(s) and the source, provide a link to the Creative Commons licence, and indicate if changes were made. The images or other third party material in this article are included in the article's Creative Commons licence, unless indicated otherwise in a credit line to the material. If material is not included in the article's Creative Commons licence and your intended use is not permitted by statutory regulation or exceeds the permitted use, you will need to obtain permission directly from the copyright holder. To view a copy of this licence, visit http:// creativecommonshorg/licenses/by/4.0/.

\section{References}

Afargan H, Kaspi Y (2017) A midwinter minimum in North Atlantic storm track intensity in years of a strong jet. Geophysical Research Letters 44:12,511-12,518. https://doi.org/10.1002/ 2017GL075136

Bengtsson L, Hodges KI, Roeckner E (2006) Storm tracks and climate change. J Climate 19:3518-3543. https://doi.org/10.1175/ JCLI3815.1

Blackmon ML, Wallace JM, Lau NC, Mullen SL (1977) An observational study of the northern hemisphere wintertime circulation. J Atmos Sci 34(7):1040-1053. https://doi.org/10.1175/15200469(1977)034<1040:AOSOTN > 2.0.CO;2

Blender R, Fraedrich K, Lunkeit F (1997) Identification of cyclonetrack regimes in the North Atlantic. Q J Roy Meteorol Soc 123(539):727-741

Brooks CE (1946) Annual recurrences of weather: "singularities": Part I. Weather 1:107-113. https://doi.org/10.1002/j.1477-8696.1946. tb00051.x

Chang E (2001) GCM and observational diagnoses of the seasonal and interannual variations of the Pacific storm track during the cool season. J Atmos Sci 58:1784-1800. https://doi.org/10.1175/15200469(2001)058<1784:GAODOT > 2.0.CO;2

Christoph M, Ulbrich U, Speth P (1997) Midwinter suppression of Northern Hemisphere storm track activity in the real atmosphere and in GCM experiments. J Atmos Sci 54:1589-1599. https://doi.org/10.1175/1520-0469(1997)054<1589:MSONHS> 2.0.CO;2

Copernicus Climate Change Service (C3S) (2017) ERA5: Fifth generation of ECMWF atmospheric reanalyses of the global climate. https://cds.climate.copernicus.eu/cdsapp\#!/home

Deng Y, Mak M (2005) An idealized model study relevant to the dynamics of the midwinter minimum of the Pacific storm track. J Atmos Sci 62:1209-1225. https://doi.org/10.1175/JAS3400.1

Duchon CE (1979) Lanczos filtering in one and two dimensions. J Appl Meteorol 18(8):1016-1022. https://doi.org/10.1175/15200450(1979)018<1016:LFIOAT > 2.0.CO;2

Feser F, Barcikowska M, Krueger O, Schenk F, Weisse R, Xia L (2015) Storminess over the North Atlantic and northwestern Europe-A Review. Q J Roy Meteorol Soc 141(687):350-382

Godfrey CM, Wilks DS, Schultz DM (2002) Is the january thaw a statistical? Bull Am Meteorol Soc 83(1):53-62. https://doi.org/10. 1175/1520-0477(2002)083<0053:ITJTAS > 2.3.CO;2
Hatzianastassiou N, Papadimas CD, Lolis CJ, Bartzokas A, Levizzani V, Pnevmatikos JD, Katsoulis BD (2016) Spatial and temporal variability of precipitation over the Mediterranean Basin based on 32-year satellite Global Precipitation Climatology Project data, Part I: Evaluation and climatological patterns. Int $\mathrm{J}$ Climatol 36(15):4741-4754. https://doi.org/10.1002/joc.4666

Hersbach H, Bell W, Berrisford P, Horanyi A, MS J, Nicolas J, Radu R, Schepers D, Simmons A, Soci C, Dee D (2019) Global reanalysis: Goodbye ERA-Interim, Hello ERA5. ECMWF Newsletter 159:17-24. https://doi.org/10.21957/vf291hehd7

James I (1987) Suppression of baroclinic instability in horizontally sheared flows. J Atmos Sci 44(24):3710-3720

James I, Gray L (1986) Concerning the effect of surface drag on the circulation of a baroclinic planetary atmosphere. Q J Roy Meteorol Soc 112(474):1231-1250

Kästner M, Kriebel KT (2001) Alpine cloud climatology using longterm noaa-avhrr satellite data. Theor Appl Climatol 68(3-4):175195

Liao C, Xu H, Deng J, Zhang L (2018) Interannual Relationship between ENSO and Atlantic storm track in spring modulated by the Atlantic multidecadal oscillation. Atmosphere 9:1-16. https://doi.org/10.3390/atmos9110419

Lorenz EN (1955) Available potential energy and the maintenance of the general circulation. Tellus 7(2):157-167. https://doi.org/10. 1111/j.2153-3490.1955.tb01148.x

Ma X, Zhang Y (2018) Interannual variability of the North Pacific winter storm track and its relationship with extratropical atmospheric circulation. Climate Dynam 51:3685-3698. https://doi.org/10.1007/s00382-018-4104-8

Nakamura H (1992) Midwinter suppression of baroclinic wave activity in the Pacific. J Atmos Sci 4:1629-1642. https://doi.org/10.1175/ 1520-0469(1992)049<1629:MSOBWA > 2.0.CO;2

Neu U, Akperov MG, Bellenbaum N, Benestad R, Blender R, Caballero R, Cocozza A, Dacre HF, Feng Y, Fraedrich K et al (2013) Imilast: a community effort to intercompare extratropical cyclone detection and tracking algorithms. Bull Am Meteorol Soc 94(4):529-547

Řezničkovả L, Brảzdil R, Tolasz R (2007) Meteorological singularities in the Czech Republic in the period 1961-2002. Theor Appl Climatol 88:179-192. https://doi.org/10.1007/s00704-006-0253-5

Rogers JC (1997) North Atlantic storm track variability and its association to the North Atlantic oscillation and climate variability of Northern Europe. J Clim 10:1635-1647. https://doi.org/10.1175/ 1520-0442(1997)010<1635:NASTVA > 2.0.CO;2

Tamarin T, Kaspi Y (2017) The poleward shift of storm tracks under global warming: a Lagrangian perspective. Geophys Res Lett 44:10,666-10,674. https://doi.org/10.1002/2017GL073633

Tomczyk AM (2016) Thermal conditions relative to atmospheric circulation in the christmas period in Poland. Quaestiones Geographicae 35(1):47-56

Trigo IF (2006) Climatology and interannual variability of stormtracks in the Euro-Atlantic sector: a comparison between ERA40 and NCEP/NCAR reanalyses. Climate Dynam 26:127-143. https://doi.org/10.1007/s00382-005-0065-9

Wahl EW (1953) Singularities and the general circulation. J Meteorol $10(1): 42-45$

Woollings T, Hannachi A, Hoskins B (2010) Variability of the North Atlantic eddy-driven jet stream. Q J Roy Meteorol Soc 136:856868. https://doi.org/10.1002/qj.625

Publisher's note Springer Nature remains neutral with regard to jurisdictional claims in published maps and institutional affiliations. 